\title{
GESTIÓN PATERNALISTA Y TECNOLOGÍA, UNA ELECCIÓN COMPLEJA. LA COMPAÑÍA CARBONÍFERA E INDUSTRIAL DE LOTA (1920-1940)*
}

\author{
PATERNALISTIC MANAGEMENT AND TECHNOLOGY, A COMPLEX CHOICE. \\ THE COAL AND INDUSTRIAL COMPANY OF LOTA (1920-1940)
}

\author{
Hernán Venegas Valdebenito** y Diego Morales Barrientos**
}

\begin{abstract}
El propósito de este artículo es analizar la formulación y algunos de los resultados del modelo de gestión paternalista del trabajo manejado por la Compañía Minera e Industrial de Chile y su incongruencia respecto de una más lenta y difícil modernización productiva. Así, se propone que el importante papel desempeñado por la fuerza de trabajo adiestrada en un contexto paternalista, particularmente la actividad de los barreteros, fue insuficiente para sostener el crecimiento productivo sin una adecuada modernización de las labores extractivas, lo que finalmente incidió en el deterioro de la capacidad de las compañías para asegurar el abastecimiento energético nacional.
\end{abstract}

Palabra claves: Minería carbonífera, trabajo, producción, barreteros.

This article analyzes the design and some results of the "paternalist model" in the Mining and Industrial Company of Chile. According to this objective, variables such as output and productivity are analyzed. The article also describes the traditional work done by "barretros", or miner whose working tool was the crow bar. The article also examines the limitations and eventual collapse of the "paternalists model".

Key words: Coal mining, labor, output, barreteros.

\section{Introducción}

La industria del carbón de la primera mitad del siglo XX fue una de las actividades más dinámicas y de mayor envergadura económica del país. Con asiento en las localidades de Lota, Coronel, Curanilahue y Lebu, las compañías Minera e Industrial de Chile y la Carbonífera y de Fundición Schwager, emplearon a miles de trabajadores mineros y se convirtieron en el sustento del mercado energético nacional, al extraer y comercializar más del $80 \%$ de la producción de los yacimientos carboníferos situados en el golfo de Arauco (Venegas 1998).

Esta industria requirió de una mano de obra estable y disciplinada para su funcionamiento, incentivo suficiente para que la Compañía Minera e Industrial Chile, convertida en 1933 en la Compañía Carbonífera e Industrial de Lota (CCIL), desarrollara un modelo de gestión con claras orientaciones paternalistas durante los años veinte y treinta, tal como ese modelo es definido en la literatura especializada (Sierra 1991; Vergara 2013; Venegas 2014, 2015), luego que inaugurara un Departamento de
Bienestar para articular sus relaciones con el mundo del trabajo. Esta estrategia fue útil al intervenir entre los trabajadores mineros altamente organizados y movilizados, pero menos en la tarea de transformar las prácticas laborales de los operarios en los socavones carboníferos, pues la explotación siguió dependiendo del trabajo de barreteros, contratistas $\mathrm{y}$ apires, quienes se desempeñaron con relativa autonomía en el fondo de las minas. De tal forma, esa cuota de autonomía contrastó con la prolífica regulación de la vida obrera propuesta por la industria en el exterior, al intentar modelar y supervisar las instalaciones de naturaleza urbana que ella misma había edificado en Lota Alto, distrito donde miles de familias se habituaron a la vida en pabellones habitacionales, plazas, teatros y amplias calles pavimentadas (Venegas, 2014; Godoy, 2015).

Esta estrategia laboral fue aprovechada por la compañía minera en una primera fase de expansión productiva en la década de 1910 pero se intensificó en las décadas siguientes luego que el conflicto obrero-patronal alcanzara una envergadura mayor durante el ciclo huelguístico de 1919-1924 (Barría

\footnotetext{
* Resultado proyecto FONDECYT No 1120449.

** Universidad de Santiago de Chile, Santiago, Chile. Correo electrónico: hernan.venegas@usach.cl; diego.morales@usach.cl
} 
1960: 280-313; Grez 2011:181-193). Si esto es correcto, las empresas del carbón sostuvieron un modelo de gestión más preocupado por conciliar las relaciones del trabajo -disminuir el número de días no trabajados- que aumentar o expandir los rendimientos del negocio carbonífero entre 1920 y 1950, un fenómeno semejante al planteado por Richard Price (1986:97) al reflexionar por qué en Inglaterra, epicentro de la primera revolución industrial, la mecanización y modernización productiva de las fábricas se mantuvieron rezagadas en relación con la economía de Estados Unidos en el inicio el siglo XX, pues entre los capitalistas ingleses habría primado un diagnóstico político por sobre el económico. A su juicio, la mecanización y la introducción de moderna tecnología en espacios industriales, al contrario de lo que se sostiene desde matrices apologéticas del empresariado, no deriva tanto de la disponibilidad de capitales o del afán innovador intrínseco de un capitalista particular, sino de condiciones contextuales específicas, referidas al interés de obtener utilidades y certidumbres en los negocios durante tiempos prolongados. Para Price, por tanto, los cambios tecnológicos no fueron adoptados en forma irracional (Price 1986: 99), sobre todo, porque como la introducción de la cadena de montaje, la alta tecnología y otras nuevas aplicaciones de la ingeniería en las fábricas implicó una transformación global de las relaciones sociales, las jerarquías laborales y el trabajo en cuanto tal (Meyer 1981:37-65; Melling 2008).

Un horizonte de esa naturaleza es el que debió estar en el fondo del surgimiento de modelos burocratizados de gestión de la mano de obra en la cuenca minera de Arauco hacia 1920, sobre todo por las dificultades intrínsecas de la minería subterránea para crear un control directo de las empresas en el último operario en la cadena de la explotación carbonífera (Jaffe 1991:49), es decir, el barretero, y el momento clave de la huelga provocada por los trabajadores mineros en dicha década-agrupados en la Federación Obrera de Chile, FOCh (Valenzuela 2013). Condiciones que, miradas en conjunto, auguraban dificultades imposibles de soslayar a los cuadros administrativos, profesionales y técnicos que organizaban la explotación de las carboníferas.

La opción de mantener las formas tradicionales de trabajo en la minería del carbón era rentable en la medida que los trabajadores se transformaran en una mano de obra dócil y disciplinada, algo conseguido solo parcialmente. Esto último fue una de las limitaciones centrales del modelo. Entre los mineros del carbón asentados en Lota Alto hubo muchos que participaron activamente de la vida asistida por la compañía minera mediante su Departamento de Bienestar, demostrando un elevado compromiso laboral, pero otros fueron menos dúctiles y siguieron la senda de la politización y filiación sindical, sobre todo aquella que pobló los diferentes barrios de Lota Bajo. Esto significó que una parte de la mano de obra minera continuara reticente a las directrices patronales e insistiera en prácticas laborales "irregulares", aun cuando los planes de sesgo paternalista interesados en crear una comunidad sustentada en diversos discursos moralizadores habían avanzado significativamente en los años veinte y treinta (Venegas y Morales 2015).

De acuerdo con esto, la gestión del trabajo paternalista en tanto estrategia laboral seguida por la CCIL para construir lógicas consensuales con el mundo obrero carbonífero tuvo serios inconvenientes en sacar todas las ventajas económicas en la década de 1930 ante la ampliación del mercado de combustible, debido a que se manifestó débil en aumentar la productividad. Esta contrariedad no supuso el colapso o liquidación de la industria, pero sí representó un cierto límite en sus posibilidades de desplegar un mayor desarrollo productivo de los piques de Lota. En tal sentido, la intromisión del Estado y las fuerzas militares a fines de los años cuarenta, pueden interpretarse como síntomas tardíos de un resquebrajamiento en el modelo paternalista erigido en la década de 1920.

Dicho modelo, en el caso de la Compañía Carbonífera e Industrial de Lota, tuvo como hitos fundacionales la construcción masiva de infraestructura habitacional y el desarrollo de servicios destinados a moldear el tiempo de ocio de la población minera (cine, teatros, escuelas, centros deportivos, etc.), buscó combatir la cultura obrera más que la transformación de las prácticas laborales de los operarios interiores de las minas. Una problemática recurrente en la historiografía social, como puede leerse en Thompson (1995), Hobsbawm (1987) y más adelante W. Sewell (1992) -por nombrar algunos historiadores estudiosos del concierto europeo-, que evaluaron con detalle las difíciles relaciones que establecieron los industriales y trabajadores de reciente proletarización. Abordando, entre otras materias, los distintos ritmos de modernización y mecanización de las fábricas para destacar la comparecencia del trabajo artesanal como fundamento 
de la actividad industrial, todavía presente en las últimas décadas del siglo XIX. Es, precisamente, lo que se proyectó en la cuenca carbonífera de la provincia del Biobío, en Chile, por cuanto uno de los rasgos predominantes entre los mineros estuvo asociado a su origen campesino y rural, imprimiendo parte de sus prácticas $\mathrm{y}$, sobre todo, sus dificultades para asumir una cultura del tiempo surgida de la regularidad del trabajo fabril y marcada por la puntualidad, adaptación a los horarios y una asistencia inalterable, tareas de proporciones que demandaba un largo camino de desarraigo y adecuación cultural, exigiendo a los trabajadores que renunciaran a los resabios agrícolas de sus propias trayectorias laborales y familiares (De Gaudemar 1981).

En el examen de estos planteamientos se ha recurrido a una cantidad dispersa de información. El desenvolvimiento económico de la CCIL ha sido construido mediante la revisión de las Actas del Directorio de la empresa (en adelante Actas), informes técnicos de ingenieros y series publicadas por la Dirección de Estadística Nacional en los años veinte y treinta. Por otra parte, el carácter tradicional del trabajo minero y principalmente del barretero como figura laboral específica ha sido pesquisado en $\mathrm{La}$ Opinión, periódico editado por el Departamento de Bienestar de la CCIL desde 1924, y El Sur, principal diario regional entre 1919 y 1944; informes de la Inspección del Trabajo, debido a la riqueza de las anotaciones realizadas por los inspectores regionales desde $1921 \mathrm{y}$, por último, fichas o prontuarios de los obreros de la compañía, conservadas por la Empresa Nacional del Carbón (ENACAR).

El artículo está organizado en tres secciones, en la primera se reconoce el desempeño económico de la compañía, sus logros productivos, las dificultades de operación y los intentos para encausar una importante masa de trabajadores, acentuándose en todo ello el análisis de la voz empresarial respecto del problema económico que enfrentaba en los años treinta. El segundo apartado busca reconocer las características principales del trabajo tradicional con que se explotaron los yacimientos y el rol de primer orden desempeñado por los barreteros, quizás el pilar fundamental en que se sostuvo la producción hasta mediados de siglo. Al mismo tiempo, se pone de relieve la precaria combinación entre un modelo de gestión paternalista de la fuerza de trabajo, y una organización productiva que mantuvo su mecánica tradicional. Finalmente se incluyen algunas consideraciones globales a modo de conclusión.

\section{La encrucijada económica de la Compañía Carbonífera}

Aunque en la década de 1930 la industria carbonífera experimentó un ciclo económico ascendente y mantuvo sus faenas en un rendimiento pleno, en las reuniones directivas de la plana mayor de la CCIL se percibía intranquilidad, que de alguna manera se transfirió a las esferas estatales, en una coyuntura en que las autoridades de gobierno estaban empeñadas en una intervención más activa en el fomento económico y preocupadas por la estabilidad social, tal como es posible evidenciar en las administraciones de los presidentes Alessandri e Ibáñez.

La creciente demanda de carbón en el mercado interno contrastaba con una situación productiva compleja de resolver en el corto plazo, a causa de la propia naturaleza del mineral y la dependencia de la contratación masiva de trabajadores, no siempre disponibles a mantenerse con regularidad en sus puestos de trabajo.

La compañía minera de Lota alcanzó una explotación sin precedentes en los años treinta, dejando atrás la inestabilidad y crisis propia de la década anterior debido a una combinación de factores en los mercados, donde predominaba la creciente importación de petróleo norteamericano y un elevado índice de huelgas (Venegas 1998). Con excepción del bienio 1931-1932, cuando disminuyeron las faenas extractivas, la crisis económica en los piques carboníferos se diluyó a partir de 1933. Ese ciclo recién tuvo un declive parcial en 1939, a raíz del terremoto con epicentro en Chillán, revelándose la fragilidad del orden construido por la empresa en Lota Alto al impedir que cientos de familias tuvieran asegurado un "techo" para su mantenimiento. El nivel de esa problemática fue aquilatado por el directorio de la CCIL, cuando en agosto de 1939 calculaba que, de las 1.833 casas utilizadas por obreros en Lota Alto, 95 sufrieron pequeños daños, 1.050 tuvieron daños de importancia, 598 se consignaron como muy afectadas, mientras que 90 fueron totalmente destruidas (Acta $\mathrm{N}^{\circ} 5$ CCIL, 24/08/1939:217).

El terremoto, en todo caso, no modificó un ápice el ciclo expansivo que experimentó la industria en los años treinta y un buen indicador de ello es el número de trabajadores contratados por las compañías y, en particular, la CCIL. Según el ingeniero Ricardo Fenner (1937:423), que en más de alguna ocasión realizó estudios por encargo a la Junta Directiva 
de la empresa en la década de 1940, el número de obreros pasó de 5.054 a 7.451 entre 1932 y 1937. Otro síntoma de la bonanza se constata en el hecho de que los piques de Lota superaron el cincuenta por ciento del carbón nacional extraído en 1935 (Fenner 1936:434). La envergadura de la empresa, por ello, se multiplicó en relación con su primera gran expansión producida en los años de la Primera Guerra Mundial, respondiendo favorablemente a dos estímulos cruciales. Por un lado, la mayor demanda en el mercado nacional y, por el otro, la protección estatal respecto del petróleo y carbón importado impulsada por Ibáñez, luego que se aplicaran las consideraciones sugeridas por la Comisión del Carbón publicadas en 1926, cuando la industria, a pesar de su importancia, estuvo en entredicho.

La intranquilidad de la plana directiva de la CCIL, por tanto, no se originaba en los volúmenes producidos, sino en sus inconvenientes para abastecer con regularidad el mercado nacional en ampliación, debido al aumento de requerimientos de carbón en la red de ferrocarriles del Estado, la marina mercante, el sector industrial y las compañías termoeléctricas. El problema, reconocido por la directiva empresarial, radicaba en las dificultades para "exceder la producción" en los yacimientos:

El Gerente hizo presente que el mercado consumía la totalidad de la producción de carbón horneado que las minas entregaban y que había ordenado estudiar la forma de aumentar en lo posible la actual explotación y del estudio hecho resultaba que el "Pique Grande" no puede por ahora aumentar porque su capacidad de extracción está en su límite máximo (Acta No 4 CCIL, 26/07/1934:87).

A la sazón, el Pique Grande era la faena más importante que tenía la compañía, pero por su antigüedad era limitada la opción de ampliarla. Por lo mismo, la tarea era resolver el inicio de una nueva explotación como se hizo con la apertura en 1942 del Pique Carlos Cousiño. Este laboreo había sido proyectado en 1930, aunque las obras de apertura requirieron un prolongado tiempo y sucesivas inversiones. Entre 1933 y 1937 el Directorio de la CCIL aprobó una inversión de \$7.500.000 solo para abrir el túnel doble y los primeros accesos interiores ${ }^{1}$. Se invirtieron otros \$ 5.696.836 para diseñar la estructura interna de las galerías de operaciones y servicios, pero en 1939 todavía se calculaba que "el costo que falta por invertir hasta llegar al carbón será más o menos sobre $\$ 10.000 .000 "$ (Acta $\mathrm{N}^{\mathrm{o}}$ 5 CCIL, 27/01/1940:249.). Con ese panorama, la situación de la industria del carbón era compleja porque estaba condicionada a "incrementar la explotación de las minas al máximo, aun a riesgo de aumentar el costo de explotación" (Acta $\mathrm{N}^{\circ} 4$ CCIL, 23/05/1936:240).

El camino para extraer carbón de los mismos yacimientos en Lota implicaba introducir mejoras parciales en los dos piques y el chiflón, explotaciones que ya tenían su propia fisonomía considerando el diámetro de las galerías, la capacidad máxima de obreros por turno y un número determinado de cajones en circulación. Cambios en alguna de esas condiciones eran parte de las escasas alternativas que los ingenieros colocaron sobre la mesa del Directorio de la CCIL para responder a los mandatos que los compelían a aumentar la explotación. Sin embargo, en la práctica, sus órdenes significaban un incremento en la presión de la mano de obra, por cuanto se advertía la necesidad de intensificar el trabajo sin necesidad de implementar transformaciones relevantes en las faenas. Más trabajo y compromiso laboral, era la consigna que por esos mismos años se instaló en las altas autoridades políticas del país, quienes no dudaron en situar al carbón y a sus trabajadores en el centro del proyecto industrializador del país (Pavilack 2011).

La mecanización de la actividad carbonífera tenía sus propias complejidades o limitaciones. No siempre era posible introducir maquinaria en reemplazo de los obreros en el fondo de las galerías en socavones que tenían su propia historia y antigüedad, condiciones específicas para su electrificación, ventilación y humedad de los mantos. Por lo demás, no siempre era recomendable invertir en yacimientos con una vida útil decreciente, sobre todo cuando su organización productiva todavía se encontraba en plena actividad. Fruto de estas consideraciones, el cuerpo de ingenieros de la CCIL solo a mediados de 1936 propuso estudiar con seriedad la ampliación de la mecanización, aunque de manera tentativa porque el objetivo era "determinar la suma que sería necesario invertir" (Acta No 4 CCIL, 25/06/1936: 248). Un cambio acometido con lentitud, porque casi diez años más tarde y tras la muerte de 18 obreros en una explosión repentina del gas grisú, el diputado comunista Damián Uribe -ex obrero del carbón- consultando cifras oficiales de 1942 señalaría que la mecanización en la industria carbonífera no superaba el 25 por ciento en alusión a los "frentes de ataque" en operaciones en aquella época (Uribe 1947: 534) 
La industria no modernizó intensamente sus activos de capital en los años treinta y cuando lo hizo en 1934 buscó optimizar de preferencia el transporte interior de sus minerales y en particular en el Pique Grande. El ítem maquinarias en los Balances Generales anotados en los libros de Actas fue de 657.465 pesos en 1934 , $\$ 732.495$ en 1936 y $\$ 762.759$ al año siguiente, estimaciones que involucraban las existencias de las actividades agrícolas, forestales, industriales, mineras y de transporte, que a la sazón comprendía la totalidad del complejo empresarial de la CCIL. De allí que los cálculos del ingeniero Hugo Gardner, referente al ítem maquinaria propiamente minera en los tres establecimientos de Lota en 1934, cercanos a los 182.577 pesos, sirven como medida más equilibrada para la estimación del valor de la maquinaria efectivamente utilizada en el interior de los laboreos (Acta No 4 CCIL, 19/04/1934:67). Un monto que comprendía ventiladores, bombas de extracción y lámparas eléctricas, calderas, canoas transportadoras, perforadoras, compresoras de aire y circadoras. Siendo solo estas últimas el material destinado a reemplazar u optimizar el trabajo directo de los barreteros (Fenner 1937:424-425).

Según esto, el empeño de la CCIL por aumentar la producción de carbón durante los años treinta descansó por sobre otros en la gestión del trabajo, materia en la que se buscó regular las actividades productivas desarrolladas por los operarios interiores, intentando intensificar el trabajo diario. Este es el fundamento que ayuda a comprender el acento empresarial por la asistencia al trabajo, piedra angular por las que el Código del Trabajo buscó incidir en el mundo asalariado al ofrecer vacaciones pagadas solo a quienes cumplieran mínimos de regularidad laboral cada año. En la mirada de la plana directiva, la inasistencia era la responsable de su incapacidad para hacer frente al incremento del mercado interno de carbón debido a una tríada nefasta constituida por la combinación del "feriado obrero, las enfermedades y muy principalmente a la embriaguez" (Acta N 5 CCIL, 7/10/1937:85). Las tres señales de indisciplinas recurrentes impedían una cuota mayor de producción en Lota.

De esa interpretación también se hizo eco la Sociedad Nacional de Minería al sentenciar en 1939 que los problemas de abastecimiento del combustible percibidos en 1938 tenían como origen la agitación obrera y el alcoholismo -no las empresas del rubro-, ya que contribuían "en forma decisiva al desquiciamiento de la disciplina, de la regular asistencia al trabajo y de la normal eficiencia que los operarios deben desarrollar en el desempeño de sus labores" (Álvarez 1940:47). Por lo mismo, las autoridades políticas no dudaron en emprender medidas de "emergencia" para combatir la embriaguez en la región del carbón y respaldaron la iniciativa de las compañías mineras de Arauco, en orden a decretar una Zona Seca en Lota, Coronel y Lirquén (en discusión desde mayo 1941 y con reflujos hasta por lo menos 1942) (La Nación 25/05/1941:14), haciéndose cargo, policialmente, de las innumerables grietas abiertas por el mercadeo ilegal entre productores, bodegueros y cantineros, así como el denunciado por El Sur al dar cuenta del tráfico existente en el sector "Arreglín" en las cercanías de Lota (31/05/1941:9).

La asistencia al trabajo fue una temática de permanente preocupación en la industria carbonífera de Lota porque afectaba el desempeño económico de sus operaciones en una escala difícil de calcular, aunque muchas veces se le cifró en $15 \%$ de la plantilla total de trabajadores. Por eso su órgano portavoz, La Opinión, se allanó a visualizar los efectos que acarreaba la inasistencia laboral en forma recurrente, señalando que:

Los que faltan al trabajo en los primeros días de la semana, corren mayor peligro de perder su puesto. Al iniciarse las faenas el día lunes, perjudica enormemente la falta de un barretero, de un contratista, de un carretillero. Se pierde tiempo en buscarle reemplazante y todo el servicio se resiente (La Opinión 1/05/1934:1).

Con informaciones similares, el mismo periódico instaló en Lota el interés de la industria por el mantenimiento de la regular asistencia y remarcaba la necesidad de estabilizar la cadena de trabajo establecida entre los barreteros, contratistas y los apires, quienes por turno y en jaulas mecánicas bajaban al fondo de la mina para iniciar un desplazamiento interior caminando hasta los frentes de trabajo, en no menos de 40 minutos de recorrido, distancias superiores a los tres kilómetros desde la bocamina (Muñoz 1935:398-399). Una cadena alterable por la inasistencia de alguna de sus piezas, "interrumpiendo el ritmo de la producción y echando a perder los cálculos de productores y de consumidores" como sucedió con los:

Verdaderos récords de inasistencia se batieron los días 2 de enero siguiente de año nuevo; el 6 de febrero y el 6 de marzo siguientes de la cancelación, en que la proporción de falleros aumentó al 
doble. El sábado 7 de marzo, víspera de fiesta ( $L a$ Opinión 1/05/1936:3).

El perjuicio esgrimido desde la empresa por prácticas de esta naturaleza fue un aliciente más que se evaluó en la edificación de un Departamento de Bienestar en Lota. La inasistencia derivaba de una "incomprensión" cultural del trabajo y, más exactamente, del uso del tiempo libre y de los espacios ajenos a la producción por parte de los mineros. Por lo mismo, la compañía intentó remediar esas prácticas mediante planes de intervención que difundieran nuevos modelos de comportamiento entre las familias mineras, invitándolas a asumir valores como la responsabilidad, ahorro, previsión y productividad (Venegas y Morales 2015). Fue la preocupación medular del modelo de gestión paternalista en Lota, justificado en la necesidad de mejorar la asistencia al trabajo y, en general, los "deberes" de los obreros carboníferos con la industria.

Con este anhelo la compañía realizaría, en enero de 1935, un cambio sustancial en la forma como se pagaban las remuneraciones, estableciendo una única ventanilla y planilla de pago por mes, centralizando un sistema que previamente permitía a los obreros recibir su salario en forma semanal, quincenal o mensual durante los días sabados, en oficinas distribuidas en cada uno de los piques y otras secciones de la empresa. Esto requirió por parte del establecimiento de una Oficina Central de pago en Lota y la contratación de más pagadores por la estrechez de las antiguas oficinas de canje. Con este cambio se esperaba disminuir la embriaguez recurrente de los fines de semana entre los obreros (y con ello el "san lunes") y el fortalecimiento de una cultura del ahorro entre las familias mineras, en tanto el salario mensual exigía un uso más racional al requerir una programación del conjunto de gastos familiares, durante cada mes. En esta dirección, el periódico La Opinión destacó en diferentes columnas de opinión las bondades del nuevo sistema identificando como la principal beneficiada a la dueña de casa, ya que con la reforma era "posible obtener de nuestros esposos, la papeleta de finiquito mensual y darnos cuenta de los saldos que antes iban a parar sabe Dios dónde" (La Opinión 1/05/1935:6), manteniendo un mayor control respecto del salario percibido por sus respectivos esposos.

Para la empresa el consumo de alcohol también fue un factor en la seguridad de las minas, lo que destacó en forma reiterativa en su campaña
"Seguridad ante todo". La inseguridad no desquiciaba la disciplina laboral como sí la causaba el alcoholismo, pero tenía repercusiones claras en el funcionamiento de las galerías al incidir en la disminución del ritmo laboral de las cuadrillas. Los accidentes, con saldo de heridos y muertos, paralizaban un distrito o sección de un mineral en forma continuada debido a que cada emergencia significaba ir en ayuda de un minero que implicaba la paralización momentánea del laboreo. Esto sin contar que la muerte en un accidente también generaba la inasistencia de decenas de trabajadores, sobre todo entre quienes asistían a los funerales y realizaban luto. El mismo resultado tenían los accidentes menores, que solo provocaban lesiones circunstanciales en los mineros. En tal caso, el Hospital de Lota asistía en forma regular al minero y siguiendo los conductos regulares el operario se veía compelido a tomar alguna licencia médica para asegurar su adecuada recuperación frente a alguna fractura expuesta o quemaduras, por no mencionar el caso de quienes sufrían una amputación, situación que obligaba a la empresa a mantener instalaciones, equipo y personal médico asentado en el hospital de su propiedad.

El conjunto de estas situaciones, agrupadas en la campaña de seguridad de la empresa, se originaban en una misma explicación: "la casi totalidad de los accidentes personales se producen única y exclusivamente por culpa de la propia víctima" ( $L a$ Opinión, 1/09/1928:1). Por lo mismo, se intentó disminuir el número total de accidentados que, entre 1931 y 1951, Venegas (2015:14) ha calculado en 2.072 heridos graves para el conjunto de la industria carbonífera de Arauco.

A partir de esta campaña, a los operarios se los inducía a ser precavidos en sus actividades diarias llamándolos a tener conciencia de los riesgos encerrados en el mineral, pues, de acuerdo con los ejecutivos de la compañía, muchos de los accidentes eran evitables, ya que surgían por la desidia y despreocupación individual. Pero que provocaba daños generales, al perjudicar la secuencia de 52 semanas anuales calculadas para cada obrero, viga maestra de la explotación carbonífera en piques relativamente antiguos donde era difícil y costoso renovar el material tecnológico.

Con todo, el concepto de inasistencia fue utilizado por la compañía para desglosar buena parte de los perjuicios derivados de las prácticas laborales de sus operarios que iban en detrimento directo de la 
producción, escondiendo en él síntomas efectivos de indisciplina. Sin embargo, la inasistencia, fundada en la embriaguez, las enfermedades o los accidentes sufridos de forma frecuente por los obreros carboníferos, cuando mucho explicaba una parte de las dificultades que bien reconocieron los altos directivos de la CCIL. Entre ellas tomó un lugar protagónico el carácter tradicional de las faenas y la importancia del trabajo físico efectuado diariamente por los mineros en Lota. Este es un elemento central de nuestra explicación acerca del robustecimiento del modelo de gestión paternalista en los años veinte y treinta en la ciudad de Lota, pero que también estableció las bases de sus dificultades para proyectar el negocio del carbón en las próximas décadas.

\section{El trabajo tradicional en la minería carbonífera de Lota}

La explotación de los minerales pertenecientes a la CCIL durante la primera mitad del siglo XX se sustentó principalmente en el trabajo tradicional ejecutado por sus miles de operarios, quienes se distribuyeron en una serie heterogénea de actividades y rutinas laborales. El predominio de la experiencia y pericia arraigada al trabajo minero implicó que los trabajadores consiguieron mantener cuotas relevantes de autonomía laboral frente al accionar de los ingenieros y técnicos que gestionaban la globalidad de las faenas, por lo general, desde el exterior de los socavones.

Esta particularidad de la explotación subterránea del carbón condicionó la globalidad de las faenas $\mathrm{y}$, en particular, el avance promedio de los frentes de ataque, colocando una barrera infranqueable a la industria en su deseo de expandir el negocio carbonífero durante los años treinta. Por esto, la indisciplina, conceptualizada por la gerencia bajo el rótulo de inasistencia laboral, fue una arista más o menos marginal al desafío mayor que debió enfrentar al momento de emprender caminos para expandir la producción, sustentada en la dificultad de acelerar el ritmo de trabajo diario de los operarios del carbón. En lo que aquí se expone, esta dificultad constituiría un factor central, tanto en la articulación de un modelo de gestión burocratizado (Scranton 1984:243) en las minas a partir de los años veinte como asimismo de los límites que tuvo que enfrentar dicho modelo en Lota, ya que la alternativa de regular la vida obrera en el exterior de los yacimientos -mediante la oficina del bienestar, la asistencia social $\mathrm{u}$ otras-, no fue acompañada de transformaciones en el trabajo de los operarios en el interior de las faenas mineras.

Parte de esto visualizó el ingeniero Ricardo Fenner al examinar el conjunto de la industria, y a las compañías carboníferas de Lota y Schwager en particular. En sus diferentes investigaciones, publicadas en el Boletín de la Sociedad Nacional de Minería y el Boletín del Departamento de Minas y Petróleo, subrayó la idea de que los industriales del carbón debían avanzar hacia la explotación de nuevos mantos y abrir allí una nueva fase técnica. A su juicio, las instalaciones operativas en los años treinta se encontraban en el borde máximo de sus rendimientos porque no se había "modificado la capacidad de producción de las minas sino que, principalmente, variado el número de días de trabajo" (Fenner 1936:435).

El caso de los barreteros puede considerarse paradigmático en esta dirección. Ellos eran trabajadores altamente requeridos por la industria y reconocidos entre los trabajadores carboníferos porque se encargaban de utilizar a discreción la dinamita, guías y fulminantes necesarios en los frentes de ataque. El costo de esos explosivos y de las herramientas con que trabajaban era suministrado por la compañía a precio de costo, y descontado de sus jornales que, además, debían servir para pagar a sus asistentes, convirtiéndose de ese modo en contratistas. Debido a esto fue en la "suerte" de los barreteros donde se apoyaban anualmente las proyecciones económicas de la industria, constituyendo una "pieza" insustituible de las operaciones extractivas. Por eso mismo, se les consideraba obreros especializados. Ellos tenían atribuciones en la gestión de las cuadrillas ubicadas en los puntos iniciales de la explotación y en la apertura de los nuevos ramales. Un cúmulo de tareas en las que el barretero gestionaba a los apires y carretilleros, quienes se dedicaban a recoger el carbón y tosca desprendidos de la estructura rocosa, a limpiar el terreno y movilizar el mineral hacia los vagones o cajones.

En efecto, el método de explotación utilizado en la Compañía Minera e Industrial de Chile, debido al carácter submarino de sus yacimientos, era una combinación del modelo long-wall (Arancibia 1921). Este consistía en frentes ininterrumpidos de trabajo en los que se distribuían las cuadrillas a cargo de cada barretero. Estas líneas de trabajo en el caso de Lota y Coronel eran difíciles de conseguir porque el avance se producía en galerías y 
Tabla 1. Cantidad de obreros industria carbonífera, departamento de Arauco.

\begin{tabular}{lrrrrr}
\hline \multicolumn{1}{c}{ Obreros } & 1927 & \multicolumn{1}{c}{1931} & 1932 & 1933 & 1934 \\
\hline Obreros interiores & 4.357 & 4.424 & 3.479 & 3.855 & 4.651 \\
Barreteros & 991 & 916 & 816 & 865 & 1.062 \\
Obreros exteriores & 3.131 & 2.740 & 2.326 & 2.605 & 3.326 \\
Total & 8.479 & 8.080 & 6.621 & 7.325 & 9.039 \\
\hline
\end{tabular}

Fuente: Dirección General de Estadística, Anuario de Minería e Industria, 1927-1934.

socavones de tamaños limitados, no mayores a 15 metros (Delcourt 1924:25).

En la realización de su trabajo, la cuadrilla demoraba un tiempo variable para completar cada cajón. En parte porque como lo adelantaba Oscar Urzúa, representante de la compañía de Lota en el seno de la Sociedad de Fomento Fabril, no era "posible trabajar por idénticos métodos en todas las minas", por lo mismo era imposible "emplear la misma calidad i cantidad de maquinarias en todas las esplotaciones" (SOFOFA 1922:11:712), ya que cada lugar conllevaba operaciones imposibles de abordar con una misma regla. Incidía la dureza de la veta, el tiempo que se debía esperar para que decantara el exceso de polvo tras la explosión de dinamita, la escasez eventual de aire "limpio", la necesidad de enmaderar los metros avanzados cada día, el uso de maquinaria por parte del barretero o, simplemente, la distancia que el frente tenía respecto de los carros mecánicos, en la medida que determinaba la cantidad de paladas de material que debía realizar cada apir al cargar un cajón (Barría 1960:69-70).

Es así como los barreteros, en palabras de un senador comunista, fueron "los obreros que producen, propiamente, el carbón" (Ocampo 1947:792) y por lo mismo se distinguieron entre las muchas categorías de trabajadores, ocupados como carretilleros, corredores, plancheros, camineros, revuelteros, porteros y aceitadores.

En las faenas mineras, los barreteros no constituían más del diez por ciento de los operarios, aunque esa cifra se elevaba a cerca del 25 por cien al considerarse exclusivamente los operarios interiores contratados por las compañías carboníferas con asiento en el departamento de Arauco -Lota y Schwager-, así como se evidencia en la Tabla 1.

La importancia productiva de los barreteros no pasó inadvertida en la década de los años veinte y treinta. Incorporados a la estadística se convertirían en indicadores útiles para evaluar regularmente el estado general de la industria carbonífera, construyéndose estimaciones de sus respectivos rendimientos diarios y mensuales. Son dichos indicadores los que permiten aproximarse al problema productivo planteado a la CCIL, en la medida que es posible advertir una importante continuidad en las cifras del rendimiento diario que durante los años treinta mantuvieron los barreteros (Tabla 2), luego de disiparse la crisis en 1933.

Tabla 2. Rendimiento promedio diario por trabajador en la industria carbonífera nacional $(\mathrm{kg})$

\begin{tabular}{cccc}
\hline Años & Barreteros & $\begin{array}{c}\text { Obreros interior } \\
\text { con barreteros }\end{array}$ & $\begin{array}{c}\text { Días } \\
\text { trabajados }\end{array}$ \\
\hline 1920 & 2.591 & 653 & 220 \\
1921 & 2.837 & 541 & 247 \\
1922 & 2.850 & 553 & 224 \\
1923 & 3.008 & 619 & 241 \\
1924 & 3.047 & 668 & 262 \\
1925 & 3.401 & 701 & 233 \\
1926 & 3.151 & 712 & 262 \\
1927 & 3.703 & 768 & 243 \\
1928 & 4.411 & 838 & 216 \\
1929 & 4.596 & 804 & 279,6 \\
1930 & 4.658 & 803 & 258,9 \\
1931 & 5.046 & 974 & 191 \\
1932 & 5.058 & 935 & 183,3 \\
1933 & 4.858 & 920 & 256,3 \\
1934 & 4.839 & 916 & 272 \\
1935 & 4.780 & 862 & 289 \\
1936 & 4.752 & 807 & 293,5 \\
\hline
\end{tabular}

Fuente: Boletín del Departamento de Minas y Petróleo 1937:231.

Además, la serie muestra un problema en el mediano plazo, pese a la positiva impresión resultante del aumento casi al doble del rendimiento promedio de los barreteros si se comparan los datos de 1920 $(2.591 \mathrm{~kg})$ y $1936(4.752 \mathrm{~kg})$. El inconveniente que encierran dichas cifras se desprende del hecho que, durante los primeros meses de 1920, un barretero medio de los establecimientos de Lota ya alcanzaba 4.374 kilos diarios, eso sí, cuando todavía no se 
iniciaba la implementación del nuevo régimen de ocho horas de trabajo continuado, el sábado inglés y descanso dominical obligatorio ${ }^{2}$.

En función de estos antecedentes, la serie del rendimiento diario promedio por barretero puede ser evaluada con ponderación. Es cierto que se aprecia una proyección ascendente en la cantidad de kilos obtenidos diariamente por los barreteros, pero difícilmente puede colegirse que la explotación sufrió una alteración profunda y con ello una transformación en la actividad de las cuadrillas de los frentes de ataque. En similar dirección, el ya mencionado senador Ocampo (1947:792), considerando la estadística entre 1936 y 1946, señaló que en la industria carbonífera de la provincia de Concepción "el barretero produce más o menos lo mismo", para replicar la afirmación recurrente de que ellos venían disminuyendo su contribución a la extracción del carbón regional.

Según esto, la minería carbonífera de Lota entre 1920 y 1940 descansó en un obrero minero prototípico, como lo era el barretero. Un obrero que, debido a su importancia productiva, sería el blanco de los intentos de fidelización, regulando sus comportamientos, especialmente para obtener de ellos una asistencia laboral inalterable como se destacó, por ejemplo, en el caso del barretero José Eucarpio Avello contratado por la Compañía Carbonífera e Industrial de Lota entre 1926 y 1965. En correspondencia con su extraordinaria continuidad laboral fue bien calificado por el Departamento de Bienestar (en 1942), por lo que no resulta extraño que dos años más tarde se hiciera merecedor del usufructo de una casa en forma gratuita y, varios años después, consiguiera un reconocimiento y premios (en 1957 y 1961). Estímulos materiales que iban de la mano con el privilegio de mantenerse como barretero dentro de la industria, un trabajo altamente cotizado porque retribuía los mayores salarios del mundo obrero carbonífero (ENACAR, Prontuario $\left.\mathrm{N}^{\mathrm{o}} 8, \mathrm{~s} / \mathrm{f}\right)^{3}$.

Trayectorias como la de José Avello son indicativas del argumento general hasta aquí sostenido, referido al establecimiento de un cierto agotamiento o límite que imponía el paternalismo como modelo de gestión del trabajo en Lota. Pues se ocupó prioritariamente de utilizar hasta el máximo su estructura dual, fundada en el contraste del trabajo tradicional en el fondo de la mina y el intento, no siempre cumplido, de regulación de la vida obrera en el exterior de los yacimientos. Gracias a ella conseguiría ampliar la producción en épocas de expansión, pero no en el mediano plazo (década de 1940), en tanto se mantuvo el trabajo tradicional efectuado por los obreros mineros, organizados celularmente en cuadrillas que gozaban de autonomía a pesar de los cambios más globales en la gestión administrativa de la empresa.

$\mathrm{Al}$ ocuparse de sus establecimientos en Lota, la compañía enfatizó la optimización de su gestión interna en atención al número creciente de operarios que diariamente bajaban a los piques. Así lo representó, a fines de los treinta, la gerencia central al directorio pidiendo a "un ingeniero más para que se ocupe de lo relacionado con el transporte en el interior de la mina [...], es este un punto que requiere una atención especial" (Acta $\mathrm{N}^{\circ} 5$ CCIL, 20/12/1939:242). Esta arista del problema minero ocupó los mayores esfuerzos de los administradores e ingenieros, quienes identificaron en los desplazamientos de los obreros, materiales y la maquinaria un problema insoslayable en el funcionamiento de sus instalaciones, pues semana a semana la mina sumaba mayor profundidad y extensión en el subsuelo marino del golfo de Arauco. Prolongación física de los socavones que exigía una mayor cantidad de obreros dedicados al transporte, como empujas y huacheros (explicando la disminución del rendimiento de todos los obreros interiores entre 1933-1936), y una regulación más pormenorizada de las rutas por las que debían circular los trabajadores para llegar a sus espacios laborales o regresar de ellos.

En atención a lo dicho respecto de los barreteros, el planteamiento de Fenner, sobre el modelo de gestión seguido por las industrias carboníferas, cobra asidero, pues sugiere que los barreteros no incorporaron cambios profundos en sus respectivos oficios durante los años veinte y treinta al no diferir en lo sustancial los rendimientos obtenidos en uno $\mathrm{u}$ otro momento. Esto a raíz de que un barretero de los años treinta podía conseguir cifras cercanas a $4.700 \mathrm{~kg}$ diarios, los que no eran del todo inalcanzables mediante las prácticas laborales desarrolladas en 1920. En esta perspectiva, la expansión de la producción global de la industria en los años treinta fue posible por una regularización de la cantidad de días efectivamente trabajados por semana, consiguiéndose una cota cercana al máximo luego que se redujeran los días feriados y, por medio de la estandarización del sistema de pago, se acotaran los días "perdidos" por el consumo abusivo del alcohol. Esto significaba que, en vez de introducir 
alteraciones laborales, la expansión de la producción en la década de 1930 confió en el consumo límite del trabajo al servicio de la compañía.

$\mathrm{Si}$ esto es cierto, es posible comprender y relevar la significación del nuevo modelo de gestión del trabajo en la CCIL a contar de los años veinte, luego que implementara, junto con otras grandes empresas industriales del país, un programa inspirado en el paternalismo industrial. Estaba en ciernes la necesidad de encuadrar a los operarios del carbón desde el punto de vista cultural para que se incluyeran satisfactoriamente bajo las exigencias perentorias de la mina, disipando agentes disruptores del orden fabril, derivados de los conflictos obreros y la politización de sus cuadros dirigentes y asociaciones de promoción cultural, así como se manifestaron en los años más álgidos de la protesta obrera entre 1920 y 1924 (Videla et al. 2016). En contraste con dicho ciclo de "crisis de autoridad", el primer quinquenio de los años treinta mostraba, cuando menos, la disposición de los obreros a mantenerse en sus puestos de trabajo para acogerse a las pautas y normas sancionadas por las compañías carboníferas en cuanto a las condiciones de trabajo, vida y salario. Circunstancias que permitían a esas mismas empresas, no obstante su queja de improductividad e inasistencia laboral sistemática, hacer funcionar con normalidad la enorme cifra de 293,5 días de trabajo en 1936, guarismo seguramente insuperable por la obligatoriedad del descanso dominical (descontados de las cincuenta y dos semanas del año) y algunos feriados igualmente invariables en el calendario religioso (diciembre) y patriótico (septiembre) del país.

\section{Conclusiones}

La industria carbonífera fue un espacio productivo de enorme gravitación económica, social y política del país en la primera mitad del siglo XX. La Compañía Minera e Industrial de Chile con asiento en Lota, se constituyó en un modelo porque comenzó a innovar en las formas que implementó para relacionarse con sus miles de operarios, estableciendo un programa de paternalismo industrial burocratizado, en el que alcanzaron mayor distinción aquellas prácticas de control y disciplinamiento desarrollados en el mundo obrero y sus espacios de reproducción social.

Según se ha discutido en el presente trabajo, este modelo tuvo de dulce y de agraz en la medida que la capacidad empresarial para intervenir en los espacios de la reproducción-familiar y de sociabilidad- logró mitigar parcialmente el descontento y la agitación política de los sectores del trabajo en la zona carbonífera en el mediano plazo. Sin embargo, este encausamiento favorable al trabajo no habría estado acompañado de procesos de modernización productiva o, cuando menos, su aceleración en el tiempo. De tal modo, se ha buscado establecer el hecho que la industria entre 1920 y 1940 actuó solo parcial o lentamente para transformar el trabajo efectuado diariamente por sus obreros mineros en el fondo de las minas, y con ello su transformación tecnológica y de procesos fue lenta y tardía.

Sobre las espaldas de los barreteros, la CCIL, enfrentó el mayor desafío productivo que deparaba la década de 1930 en la medida que se ampliaban anualmente los requerimientos de combustible en el país. Los barreteros aumentaron en número, se los asistió con una mayor cantidad de obreros "transportistas", se les asignaron tareas propias de una subcontratación, mientras que, por otra parte, sus tareas se ejercieron en una estructura subterránea que crecía en profundidad y rigidez. Por contraste, las compañías emplearon una baja mecanización, que se concentró más bien en el transporte que en la explotación misma. Esto último combinado con un aumento de la demanda nacional exacerbó las dificultades para abastecer de carbón al país, pues, según se comentó, la base del modelo estaba en su cota máxima de producción.

En este sentido, es admisible plantearse las limitaciones económicas que impuso la implementación de un programa paternalista industrial en Lota, en la medida que sirvió como una alternativa de disciplinamiento laboral, pero que no fue acompañada con una política de modernización productiva que le diera sustento en el mediano plazo. Según esto, se ha establecido una suerte de agotamiento, luego que en esos años la industria no consiguiera -pese a declararlo- aumentar sus rendimientos y expandirse a la par del ávido mercado de consumo de combustible que crecía rápidamente. Quizá sea el caso, porque sus principales controladores estuvieron más interesados -luego de la crisis que como grupo industrial y patronal experimentaron en los primeros años veinte- en mantener ese modelo de negocio "dual", sin necesidad de alterarlo y arriesgar en ello la tranquilidad laboral que tan trabajosamente habían conseguido por medio de la política asistencial llevada a cabo por su Departamento de Bienestar Social. 


\section{Referencias Citadas}

Álvarez, P.

1940 "Nota de la Sociedad Nacional de Minería al Señor Ministro de Fomento". Boletín Minero de la Sociedad Nacional de Minería 477:1: 47-49.

Arancibia, L.

1921 La Región Carbonífera, considerada en sus aspectos social y minero. Memoria de Prueba para optar al Grado de Licenciado en Leyes y Ciencias Políticas. Universidad de Chile, Chile.

Archivo Empresa Nacional del Carbón (ENACAR)

1965 Departamento de Bienestar Social, Prontuarios del Personal, Lota Alto.

Barría, J.

1960 Los movimientos sociales de Chile desde 1910 hasta 1926. Editorial Universitaria, Santiago.

De Gaudemar, J.P.

1981 La movilización general. Ediciones de La Piqueta, Madrid.

Delcourt, E.

1924 Estudio sobre la Cuestión Carbonera en Chile. Sociedad Imprenta y Litográfica Universal, Santiago.

Fenner, R.

1937 "Informe pericial relacionado con la huelga en la Compañía Carbonífera y de Fundición Schwager". Boletín del Departamento de Minas y Petróleo 72:422-433.

Fenner, R.

1936 "Situación actual de la industria carbonera nacional". Boletín del Departamento de Minas y Petróleo 60: 7:429-457.

Godoy, M.

2015 "Las casas de la empresa: paternalismo industrial y construcción de espacio urbano en Chile: Lota, 1900-1950". Universum [online]. 2015, 30:115-136.

Grez, S.

2011 Historia del comunismo en Chile. La era de Recabarren (1912-1924). LOM, Santiago.

Hobsbawm, E.

1987 El mundo del trabajo. Estudio histórico sobre la formación y evolución de la clase obrera. Crítica, Barcelona.

Jaffe, J.

1991 The struggle for market power. Industrial relations in the British coal industry, 1800-1840. Cambridge University Press, Cambridge.

Melling, J.

2008 "Fordism and the Foreman: Labour Relations and Supervisory Trade Unionism in the American and British Automobile Industries". En Managing The Modern Workplace. Productivity, Politics And Workplace Culture in Postwar Britain, editado por J. Melling y, A. Booth, pp. 27-47. Ashgate Publishing Company, Hampshire.

Meyer, S.

1981 The Five Dollar Day. Labor Management and Social Control in the Ford Motor Company. 1908-1921. State University of New York Press, Albany.

Muñoz C., J.

1935 "Duración de las horas de trabajo en la industria carbonera". Segundo informe. Boletín del Departamento de Minas y Petróleo 44:8: 395-403.

Libros de Actas del Directorio de la Compañía Carbonífera $e$ Industrial de Lota 3, 4, 5 y 6. Museo Histórico Lota (MHL), Lota.

Ocampo, S.

Accidente en minas de carbón de Lota. Sus causas: réplica a las afirmaciones del Sr. Poklevovic. Discurso parlamentario,
Legislatura Ordinaria Sesión 12.a, Santiago, 2 de julio de 1947. Boletín sesiones Senado, pp. 783-800.

Pavilack, J.

2011 Mining for the Nation: The Politics of Chile's Coal Communities from the Popular Front to the Cold War. Pennsylvania State University Press, Pennsylvania.

Price, $R$.

1986 Labour in British Society. An interpretative history. Routledge, London and New York.

Scranton, P.

1984 "Varieties of Paternalism: Industrial Structures and the Social Relations of Production in American Textiles". American Quarterly 36:2:235-257.

Sewell, W.

1992. Trabajo y revolución en Francia: el lenguaje del movimiento obrero desde el antiguo régimen hasta 1948. Santillana, Madrid.

Sierra, J.

1990 El obrero soñado. Ensayo sobre el paternalismo industrial, Asturias (1860-1917). Siglo XXI, Madrid.

SOFOFA

1922 Actas de las sesiones del consejo Directivo. Boletín Sociedad Fomento Fabril 11:708-713.

Thompson, E.P.

1995 "Tiempo, disciplina de trabajo y capitalismo industrial". En Costumbres en común, editado por E.P. Thompson, pp. 395-452. Crítica, Barcelona.

Uribe, D.

1947 El problema del carbón y la catástrofe ocurrida últimamente en Lota. Discurso parlamentario, Sesión 14.a Ordinaria, Santiago, 2 de julio de 1947. Boletín sesiones Senado, pp. 529-536.

Valenzuela, M.

2013 "La huelga grande del carbón en Lota, Coronel y Curanilahue de 1920". Historia Actual Online 32:73-89.

Venegas, $\mathrm{H}$.

1998 "Desafíos de la industria carbonífera en Chile. Intervención del sector público en la senda del estado benefactor. 1920-1940". Revista de Historia 8:151-173.

Venegas, $\mathrm{H}$.

2015 "Políticas de bienestar y control social en la minería del carbón. Las experiencias de Lota y Coronel en el siglo XX". Atenea 511: 221-245.

Venegas, H. y Morales, D.

2015 "El despliegue del paternalismo industrial en la Compañía Minera e Industrial de Chile (1920-1940)”. Crítica 58:117-136.

Venegas, $\mathrm{H}$.

2014 "Paternalismo industrial y control social. Las experiencias disciplinadoras en la minería del carbón en Chile, Lota y Coronel en la primera mitad del siglo XX". Les Cahiers ALHIM 27 (10 abril). https://journals.openedition. org/alhim/5099

Vergara, A.

2013 "Paternalismo industrial, empresa extranjera y campamentos mineros en América Latina: un esfuerzo de historia laboral y trasnacional". Avances del Cesor 10:113-128.

Videla, E.; Venegas, H. y Godoy, M.

2016 El orden fabril: paternalismo industrial en la minería chilena 1900-1950. América en Movimiento, Valparaíso. 


\section{Notas}

1 El Pique Carlos Cousiño fue abierto en el campo del Pique Alberto, puesto que si bien era el de mejor proyección por la magnitud de sus yacimientos, su bocamina no era suficientemente adecuada para extraer el carbón explotado desde las profundidades. Por eso mismo, el Pique Carlos Cousiño fue habilitado contiguamente para solucionar en parte dicho desbalance. Al respecto, véase la discusión en el libro de Actas $N^{\circ}$ 5, 9 de abril de 1938:123.

2 Las condiciones y horarios de trabajo fueron un tópico recurrente en los conflictos obreros que causaron las grandes huelgas del carbón entre 1920 y 1924. Frente al establecimiento de las jornadas de ocho horas diarias de trabajo, las compañías carboníferas se negaron rotundamente explicando que la industria se encontraba en un período crítico derivado de inestabilidades en los mercados de consumo y la competencia del petróleo importado desde Estados Unidos. Fue en ese contexto que el Estado promovió acuerdos en los principales conflictos carboníferos creando Juntas de Conciliación y de Arbitraje. Así, en 1920 se produjeron el "Laudo Vergara", "Rivas Vicuña" y "Molina", donde los obreros forzaron el reconocimiento de la jornada de trabajo de ocho horas diarias (Arancibia 1921: 24-31).

3 La identificación de los prontuarios es difícil en la medida que el material del archivo histórico de ENACAR, consultado en oficinas de Lota Alto, carece de una organización archivística o de un catálogo. Por lo mismo el prontuario aludido corresponde al número de identificación utilizado por el mismo Departamento de Bienestar al momento de ser inscrito el operario Avello, en 1926. Este es el mismo procedimiento utilizado por Pavilack (2011). 